\title{
A Complication as a Toxic Retinopathy in a Case After Scleral-Fixed Intraocular Lens Implantation
}

\author{
Suleyman Ciftci ${ }^{\mathrm{a}, \mathrm{d}}$, Ali Simsek ${ }^{\mathrm{b}}$, Leyla Ciftci ${ }^{\mathrm{c}}$
}

\begin{abstract}
To report a complication similar a toxic retinopathy. The eye is aphakia due to trauma. The patient is a 70-year-old man. The anesthesia was applied as topically, with subtenon enjection. Two percent sodium hyaluronate (Protectalon $2 \%$ ) was used as viscoelastic and for endophthalmitis prophylaxis sefuroksim aksetil $1 \mathrm{mg} / 0.1$ $\mathrm{cc}$ was given at the end of operation. The patient complained blindness. Central retinal artery obstruction, central retinal vein occlusion, peripapiller and macular hemorrhage and optic atrophy were observed in fundus examination. After 6 months, corneal haze, especially at the upper side, occurred. It is clear that, this complication is a toxic retinopathy and a result of sequence of events. After all, a case which has resulted to such a complication due a surgery has never been reported previously.
\end{abstract}

Keywords: Central retinal artery obstruction; Central retinal vein occlusion; Corneal haze; Macular hemorrhage; Pallor of the optic nerve

\section{Introduction}

We report about a complication similar to a toxic retinopathy in a case. The operation is implantation of seconder scleralfixed intraocular lens. Obstruction of central retinal artery, occlusion of central retinal vein, peripapiller and macular hemorrhage and optic atrophy occurred right after the op-

\footnotetext{
Manuscript accepted for publication November 16, 2012

${ }^{a}$ Department of Ophthalmology, Diyarbakır Training and Research Hospital, Diyarbakir, Turkey

${ }^{b}$ Department of Ophthalmology, Faculty of Medicine, Adiyaman University, Adiyaman, Turkey

${ }^{\mathrm{c}}$ Department of Cardiology, Faculty of Medicine, Dicle University, Diyarbakir, Turkey

${ }^{\mathrm{d}}$ Corresponding author: Suleyman Ciftci, Diyarbakir Egitim ve Arastirma Hastanesi Goz Hastaliklari Poliklinigi, 21000-Diyarbakir, Turkey. E-mail:ciftci1977@hotmail.com
}

doi: http://dx.doi.org/10.4021/jmc971w eration. After 6 months, haze in the upper side of the cornea occurred (Fig. 1).

\section{Case Report}

The patient is a 70-year-old man. He does not have any disease such as diabetes mellitus or hypertension. Two years ago the patient had an accident by cow horn backlash and underwent limbocorneal suturation and anterior vitrectomy in the primer surgery and the surgery resulted in aphakia. The eye was not vitrectomised but the patient lost a large amount of vitreus during perforation. Fundoscopic examination showed normal retina and pre-operative visual acuity of the patient in the operated eye with pinholl was 0.6.

The anesthesia was applied topically with subtenon enjection and intracameral plain lidocaine was given towards the end of surgery. Two percent sodium hyaluronate was used as viscoelastic and sefuroksim aksetil was injected to anterior chamber for endophthalmitis prophylaxis. Intraocular pressure rose up to about $50 \mathrm{mmHg}, 8$ hours after operation antiglaucomatous drugs were given. Corneal edema was cleared in two weeks but the patient complained from blindness and defined only light perception. Central retinal artery obstruction, central retinal vein occlusion, peripapiller and macular hemorrhage and optic atrophy were observed in the fundus examination. This complication was not an intraocular infection because the media was clear and there was not redness or pain. After 6 months, corneal haze, especially on the upper side, occurred and the retina has become invisible. Thus, further examination such as fluorescein angiography failed due to corneal haze (Fig. 1h). This complication is similar to hemorrhagic infarction of the retina.

\section{Discussion}

The cause of this complication may be viscoelastic agents, due to the injection of lidocaine into the anterior chamber or cefuroxime. The most important postoperative complication of viscoelastic agents is elevation of intraocular pressure. Increase in intraocular pressure is dose-related and of a 

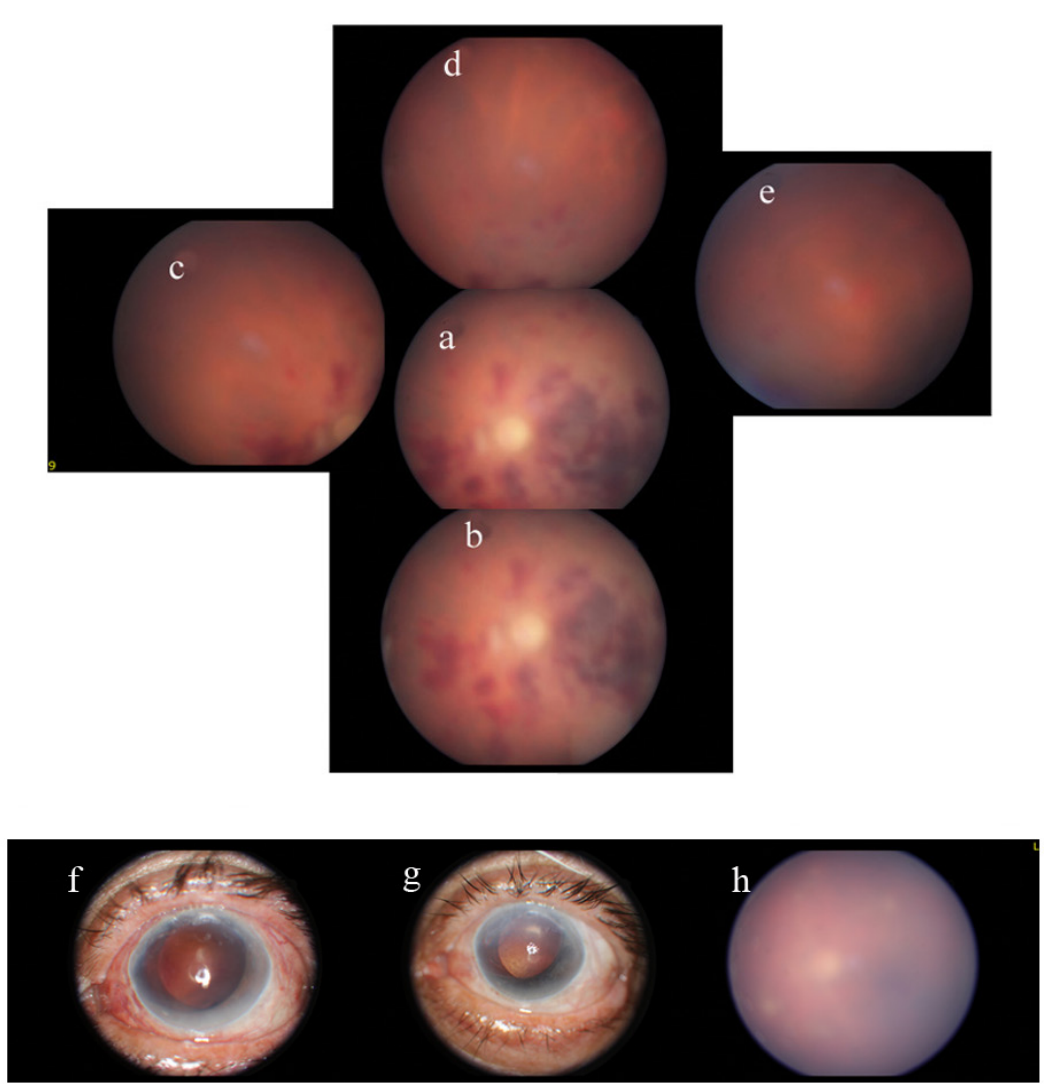

Figure 1. Fundus photograph of the eye. a: central retina, b: inferior central retina, c: superior nasal retina, $\mathrm{d}$ : superior retina, e: superior temporal retina of the eye, f: corneal photography of the eye two weeks after the operation, g: corneal photography of the eye shows development of haze 6 months after the operation, $\mathrm{h}$ : the retina has become invisible 6 months after the operation.

transient nature, generally within the first 6 - 24 hours after surgery and typically resolved within 72 hours. Increased intraocular pressure may cause central retinal vein occlusion or central retinal artery obstruction $[1,2]$. But the complication occurring in this patient was more serious than complications due to elevated intraocular pressure.

One of the other suspected substances is lidocaine. Hoffman and Fine reported transient amaurosis cases due to intracameral lidocaine [3]. Lincoff $\mathrm{H}$ and others reported retinal toxicity after injection of lidocain intraocularly [4]. Liang $\mathrm{C}$ reported electroretinogram changes in the rabbit retina but he did not observe any histologic abnormalities after injection of lidocaine hydrochloride intravitreally [5]. All the reported toxicities related to lidocaine do not cause permanent blindness whereas retinal toxicity in this case caused permanent blindness.

The most suspected substance is cefuroxime but there was not major evidence in the literature to prove so. Delyfer MN noted intracameral injection of high doses induced anterior and posterior inflammation [6]. Conversely, Sakarya $\mathrm{Y}$ and Sakarya $\mathrm{R}$ reported inadvertent intracameral $(3 \mathrm{mg}$ in $0.1 \mathrm{ml}$ ) cefuroxime injection did not cause any detectable adverse effect on ocular tissues [7].

Research for possible side effects of intracameral lidocaine, viscoelastic agents and intracameral cefuroxime were made in Medline and a few side effects were found. But these complications are not similar by the complication that we reported. Two percent sodium hyaluronate, intracameral lidocaine and cefuroxime have been used for many years and are unlikely to be the cause of the findings. The retinal hemorrages may be related to a vascular event or other pathology anytime from surgery to two weeks post-op, but this patient complained of blindness immediately after surgery and a rapidly atrophy of optic disc is not a usual presentation of vascular event. Retinal hemorrhage in this patient confined in the central, but central retinal vein, occlusion makes widespread retinal hemorrhage and visual deterioration at the level of light perception is required a much more intense bleeding.

We cannot find any related results between the abovementioned substance and the complication, however and without any doubt it developed as a whole as a result of the surgery. Overall it is clear this complication is a toxic retinopathy and a result of sequence of events resulted by hem- 
orrhagic retinal infarct. The development of corneal haze after hemorrhagic retinal infarct reinforces the idea that these complications are as result of toxicity. We think this toxicity was caused from an ingredient of the drugs or using of excess dose than the recommended dose of any drug during the operation accidentally. After all, a case which has resulted to such a complication in a surgery has never been reported previously, thus we wanted to point it out.

\section{Grant}

None.

\section{Competing Interests}

The authors declare that they have no competing interests.

\section{References}

1. Stephen S. Lane. Viscoelastic Agents: Physical Charac- teristics and Clinical Applications. Chapter 9. In: William Tasman, eds. Duane's Clinical Ophthalmology on CD-ROM. 1st ed. Philadelphia: Lippincott Williams \& Wilkins, 2006.

2. Radius RL, Finkelstein D. Central retinal artery occlusion (reversible in sickle trait with glaucoma. Br J Ophthalmol. 1976;60(6):428-430.

3. Hoffman RS, Fine IH. Transient no light perception visual acuity after intracameral lidocaine injection. J Cataract Refract Surg. 1997;23(6):957-958.

4. Lincoff H, Zweifach P, Brodie S, Fuchs W, Gross S, Kornmehl E, Krauss M, et al. Intraocular injection of lidocaine. Ophthalmology. 1985;92(11):1587-1591.

5. Liang C, Peyman GA, Sun G. Toxicity of intraocular lidocaine and bupivacaine. Am J Ophthalmol. 1998;125(2):191-196.

6. Delyfer MN, Rougier MB, Leoni S, Zhang Q, Dalbon F, Colin J, Korobelnik JF. Ocular toxicity after intracameral injection of very high doses of cefuroxime during cataract surgery. J Cataract Refract Surg. 2011;37(2):271278.

7. Sakarya Y, Sakarya R. Cefuroxime dilution error. Eur J Ophthalmol. 2010;20(2):460-461. 